\title{
The Effect of Oleic and Palmitic Acid on Induction of Steatosis and Cytotoxicity on Rat Hepatocytes in Primary Culture
}

\author{
A. MORAVCOVÁ ${ }^{1}$, Z. ČERVINKOVÁ ${ }^{1}$, O. KUČERA ${ }^{1}$, V. MEZERA ${ }^{1}$, D. RYCHTRMOC $^{1}$, \\ H. LOTKOVÁ ${ }^{1}$
}

${ }^{1}$ Department of Physiology, Charles University in Prague, Faculty of Medicine in Hradec Králové, Hradec Králové, Czech Republic

Received March 27, 2015

Accepted July 15, 2015

On-line December 15, 2015

\begin{abstract}
Summary
In vitro models serve as a tool for studies of steatosis. Palmitic and oleic acids can induce steatosis in cultured hepatocytes. The aim of our study was to verify steatogenic and cytotoxic effects of palmitic acid (PA), oleic acid (OA) and their combinations as well as their impact on functional capacity of rat primary hepatocytes. Hepatocytes were exposed to OA or PA $(0.125-2 \mathrm{mmol} / \mathrm{l})$ or their combination at ratios of $3: 1,2: 1$ or $1: 1$ at the final concentrations of $0.5-1 \mathrm{mmol} / \mathrm{l}$. Both $\mathrm{OA}$ and $\mathrm{PA}$ caused a dose-dependent increase in triacylglycerol content in hepatocytes. PA was more steatogenic at 0.25 and $0.5 \mathrm{mmol} / \mathrm{l}$ while $\mathrm{OA}$ at 0.75 and $1 \mathrm{mmol} / \mathrm{l}$. PA exhibited a dose-dependent cytotoxic effect associated with ROS production, present markers of apoptosis and necrosis and a decrease in albumin production. $\mathrm{OA}$ induced a damage of the cytoplasmic membrane from $1 \mathrm{mM}$ concentration. Mixture of OA and PA induced lower cytotoxicity with less weakened functional capacity than did PA alone. Extent of steatosis was comparable to that after exposure to $\mathrm{OA}$ alone. In conclusion, $\mathrm{OA}$ or combination of $\mathrm{OA}$ with $\mathrm{PA}$ is more suitable for simulation of simple steatosis than PA alone.
\end{abstract}

\section{Key words}

Steatosis • Palmitic acid • Oleic acid • Cytotoxicity • Apoptosis

\section{Corresponding author}

H. Lotková, Charles University in Prague, Faculty of Medicine in Hradec Králové, Department of Physiology, Šimkova 870, 50038 Hradec Králové, Czech Republic. E-mail: lotko@lfhk.cuni.cz

\section{Introduction}

Non-alcoholic fatty liver disease (NAFLD) is the most common chronic liver disease in the western countries (Tolman and Dalpiaz 2007). Histopathological picture of this disease ranges from a simple steatosis to inflammatory and fibrotic changes in the liver resulting in steatohepatitis (non-alcoholic steatohepatitis - NASH) which is a risk factor for the development of cirrhosis and hepatocellular carcinoma. Although the simple steatosis seems to be a relatively benign and reversible disease it is accompanied by enhanced oxidative stress (Gambino et al. 2011, Videla et al. 2004), higher production of proinflammatory cytokines (Braunersreuther et al. 2012) and mitochondrial dysfunction (Berthiaume et al. 2009, Garnol et al. 2014, Kučera et al. 2011, Vendemiale et al. 2001). This can result in a higher susceptibility of steatotic hepatocytes to toxic damage (Kon et al. 2010, Kučera et al. 2011, 2012, 2014) as compared with lean hepatocytes. Mechanisms of increased sensitivity of steatotic hepatocytes to various noxious stimuli should be understood so we could preserve these cells from injury.

There is rising evidence supporting the use of in vitro models as a suitable tool for studies of hepatocellular consequences of steatosis. Primary culture of hepatocytes may initially maintain the properties of the original tissue. The use of isolated human hepatocytes is still limited by legislative and ethical factors. Animal models in rats are widely used as experimental models of NAFLD. Therefore, the induction of steatosis in rat primary hepatocytes could represent a useful model for screening studies based on the sensitivity of steatotic hepatocytes. The most abundant fatty acids in the diet and in the steatotic liver are saturated palmitic acid (C16: 0) and monounsaturated oleic acid (C18: 1) (Araya et al. 
2004). Literature data confirmed the induction of steatosis in mice (Malhi et al. 2006, Tang et al. 2011, Niklas et al. 2012), goose (Pan et al. 2011) and in human (Joshi-Barve et al. 2007) hepatocytes exposed to palmitic and/or oleic acids in primary cultures as well as in immortalized hepatocyte cell lines (Gómez-Lechón et al. 2007, Mantzaris et al. 2011, Ricchi et al. 2009, Rogue et al. 2014, Swagell et al. 2005). The intracellular accumulation of triacylglycerols (TAG) was proportional to the final concentration of fatty acids in the culture medium (Ricchi et al. 2009). It is not clear whether steatogenesis is more pronounced after exposure of the cells to palmitic or oleic acid. Variability of the fat content in the hepatocytes can at least partly result from the fact that unequal concentrations of fatty acids were used. Moreover, different hepatocytes in culture models were examined in the mentioned experiments. Nevertheless, there is rising evidence that palmitic acid is more cytotoxic and proapoptotic than oleic acid (GómezLechón et al. 2011, Malhi et al. 2006, Ricchi et al. 2009).

The way how palmitic and oleic acids contribute to the development of steatosis and cytotoxicity in primary culture of rat hepatocytes as well as an impact on their functional capacity is not described sufficiently. Thus the aim of our study was to verify steatogenic and cytotoxic effects of different concentrations of palmitic acid, oleic acid and their combinations, and the influence on functional capacity of primary culture of rat hepatocytes.

\section{Methods}

\section{Chemicals}

William's E medium without phenol red, fetal bovine serum, penicillin, streptomycin and glutamine were supplied by BioChrom GmbH (Germany). Kit for lactate dehydrogenase (DiaSys, Germany), collagenase (Collagenase NB 4 Standard Grade from Clostridium histolyticum, Serva, Germany), insulin (Actrapid, Hoechst, Germany), glucagon (Novo Nordisk, Denmark), prednisolone (Merck, Germany), Cell Proliferation Reagent WST-1 (Roche, Germany), Rat Albumin ELISA Quantification Kit (Bethyl Lab. Inc., USA), Triglyceride Colorimetric Assay Kit (Cayman, USA) and Steatosis Colorimetric Assay Kit (Cayman, USA) were obtained from suppliers mentioned in the brackets. JC-1 and CM-H2DCFDA were supplied by Molecular Probes (Oregon, USA). Ac-DEVD-AMC (Caspase 3 substrate) and Ac-DEVD-CHO (Caspase 3 specific inhibitor) were delivered from Enzo Life Sciences Inc. (USA). Collagen type I, trypan blue, sodium palmitate, sodium oleate, bovine serum albumin and other chemicals were purchased from Sigma-Aldrich (USA).

\section{Animals}

Male Wistar albino rats (180-220 g, Velaz, Czech Republic) were housed at $23 \pm 1{ }^{\circ} \mathrm{C}$ with a relative humidity of $55 \pm 10 \%, 12$ to 14 air exchanges per hour and $12 \mathrm{~h}$ light-dark cycle periods $(6: 00 \mathrm{~h}$ to $18: 00 \mathrm{~h})$. The animals fed ad libitum standard pelleted diet (ST-1, Velas, Czech Republic; $10 \%$ of energy from fat, $30 \%$ of energy from proteins and $60 \%$ of energy derived from carbohydrates) and had free access to tap water. All work with animals followed the European Guidelines on Laboratory Animal Care and was approved by the Animal-Welfare Body of the Faculty of Medicine in Hradec Králové, Charles University in Prague, Czech Republic.

\section{Fatty acid preparation}

Palmitic and oleic acids were dissolved overnight in $10 \%$ fatty acids-free bovine serum albumin (BSA) in William's E medium with supplements (without serum). $8 \mathrm{mM}$ stock solutions of PA and OA (molar ratio FA and BSA 5.33:1) were further diluted with supplemented William's E medium without fetal bovine serum to final concentrations of OA, PA or their combinations as described below.

\section{Hepatocyte isolation, cultivation and treatment}

Hepatocytes were isolated by two-step collagenase perfusion from rat liver (Berry et al. 1991) with viability higher than $90 \%$ (confirmed by Trypan blue exclusion test). Isolated hepatocytes were suspended in William's E medium with supplements - fetal bovine serum $(6 \%)$, glutamine $(2 \mathrm{mM})$, penicillin $(190 \mathrm{IU} / \mathrm{ml})$, streptomycin $(190 \mu \mathrm{g} / \mathrm{ml})$, insulin $(0.08 \mathrm{IU} / \mathrm{ml})$, prednisolone $(0.05 \mathrm{mg} / \mathrm{ml})$, glucagon $(0.008 \mathrm{mg} / \mathrm{ml})$ and plated on collagen-coated 6-well $\left(1 \times 10^{6}\right.$ cells/well $)$, 24 -well $\left(2 \times 10^{5}\right.$ cells/well $)$ and 96 -well $\left(3 \times 10^{4}\right.$ cells/well $)$ plates. Hepatocytes were allowed to attach to collagen and establish a monolayer in a humidified atmosphere containing $95 \%$ air and $5 \% \mathrm{CO}_{2}$ at $37{ }^{\circ} \mathrm{C}$ for $2 \mathrm{~h}$. Then the medium was replaced with a fresh supplemented medium without fetal bovine serum with the addition of 1) oleic acid (OA) at a concentration of $0.125,0.25,0.5$, $0.75,1$ and $2 \mathrm{mmol} / \mathrm{l}, 2)$ palmitic acid (PA) at the same concentrations and 3 ) combination of $\mathrm{OA}$ and $\mathrm{PA}$ at 
a ratio $-3: 1,2: 1$ and $1: 1$ and total concentrations of 0.5 , 0.75 and $1 \mathrm{mmol} / 1$. After $24 \mathrm{~h}$ incubation, the medium was collected and cells were harvested for the required assays. A fatty acids-free vehicle served as a control.

\section{Cytotoxicity assays}

The effect of fatty acids on the viability of hepatocytes was evaluated by the activity of cellular dehydrogenases using Cell Proliferation Reagent WST-1 (Lotková et al. 2009). Cell membrane integrity was determined by the leakage of lactate dehydrogenase (LDH) from the cells using a commercial kit from DiaSys. LDH leakage is a ratio of LDH activity in the culture medium to the total LDH activity.

\section{Evaluation of steatosis}

To determine the extent of steatosis, the content of triacylglycerols (TAG) in hepatocytes was measured using the Triglyceride Colorimetric Assay Kit according to manufacturer's instructions. Results are normalized to protein concentration (Bradford 1976) and expressed as a percentage of control. The Steatosis Colorimetric Assay Kit was used to confirm the lipid droplets by Oil red $\mathrm{O}$ staining.

\section{ROS production}

The production of ROS was assessed using fluorescent probe 5- and 6-chloromethyl-2',7'-dichlorodihydrofluorescein diacetate (CM-H2DCFDA) (Kučera et al. 2014). Results were standardized to protein concentration (Bradford 1976) and expressed as a percentage of control.

\section{Caspase 3 activity}

To detect apoptosis induced by fatty acids, the activity of caspase 3 was measured using a kinetic fluorimetric method based on the hydrolysis of the specific peptide substrate Ac-DEVD-AMC (Kaiserová et al. 2006, Kučera et al. 2011). Activity of caspase 3 was normalized to protein concentration and expressed as a percentage of control.

\section{Visualization of mitochondrial membrane potential (MMP)}

MMP was depicted using cationic carbocyanine dye JC-1. At low mitochondrial membrane potential, JC-1 exerts a green fluorescence $(\lambda \mathrm{em} 525 \mathrm{~nm})$ while at higher potentials, JC-1 forms red-fluorescent "J-aggregates" ( $\lambda$ em 590 nm) (Kučera et al. 2014). MMP was visualized using fluorescence microscope Olympus IX51 (Olympus, Japan) equipped with the digital camera Olympus E600 (Olympus, Japan). Results are expressed as a percentage of cells containing mitochondria with high membrane potential of all cells.

\section{Production of albumin}

Albumin was measured by using a commercial ELISA kit obtained from Bethyl Lab. according to manufacturer's instructions. Result were standardized to protein concentration (Bradford 1976) and expressed as $\%$ of controls.

\section{Statistical analysis}

Experiments were performed at least three times using different isolations of hepatocytes. The results are expressed as means \pm SD. After testing the normality, statistical analysis was performed by one-way ANOVA (GraphPad Prism 6.01, GraphPad Software, Inc., La Jolla, CA). When significance was detected, TukeyKramer's post hoc test was used for comparisons between the different groups. $P<0.05$ was considered statistically significant.

\section{Results}

\section{Cell viability and functional capacity}

Cell viability was evaluated by LDH leakage and cellular dehydrogenase activity (WST-1). Functional capacity of hepatocytes was assessed by albumin production. Figure $1 \mathrm{~A}$ shows that PA enhanced LDH leakage from a concentration of $0.25 \mathrm{mmol} / 1(\mathrm{p}<0.001)$ while OA did not cause any damage of cell membrane integrity until the concentration of $1 \mathrm{mmol} / \mathrm{l}(\mathrm{p}<0.001)$. Similarly, production of albumin was attenuated at all tested concentrations of PA while OA lowered the production of albumin from concentration of $1 \mathrm{mmol} / \mathrm{l}$ (Fig. 1C). Cellular dehydrogenase activity declined with increasing concentrations of both fatty acids but palmitic acid caused significantly steeper decrease than oleic acid (Fig. 1B). Exposure of hepatocytes to the combinations of $\mathrm{OA}$ and PA caused increase in LDH leakage (Fig. 1A), decrease in both WST-1 (Fig. 1B) and albumin production (Fig. 1C) with rising total concentration of fatty acids and growing proportion of PA. These effects on cell viability and albumin production were significantly lower in comparison with PA alone $(p<0.001)$ at concentration corresponding to the final concentration of mixture (Fig. 1A, 1B and 1C). OA and 
A

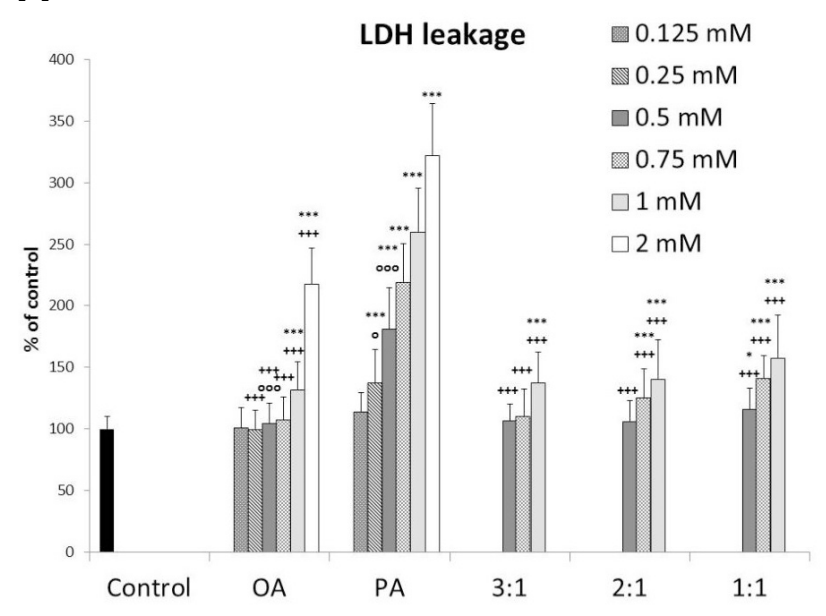

B

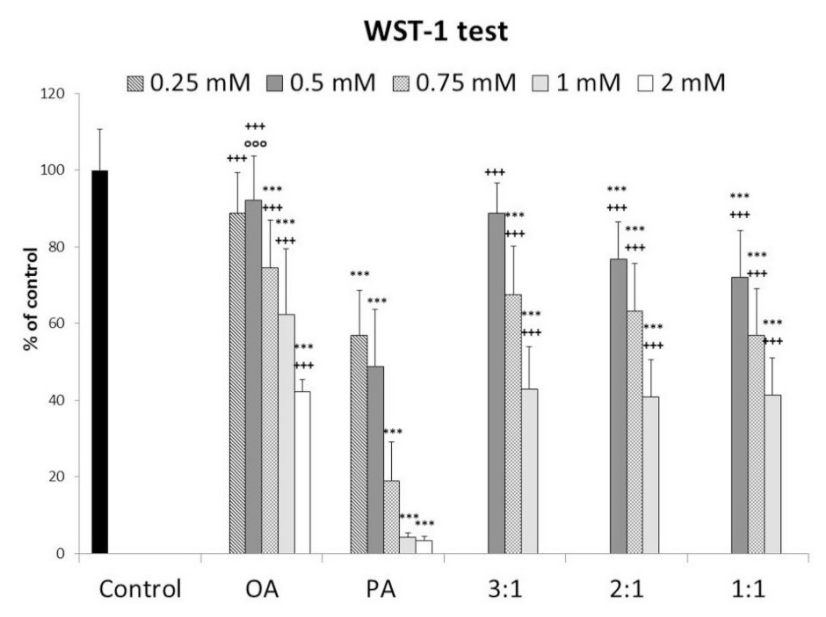

C

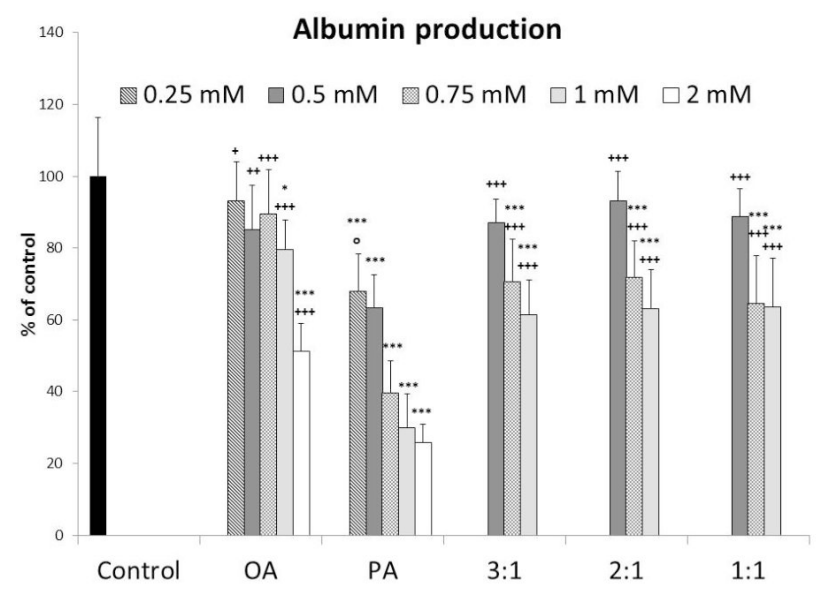

Fig. 1. LDH leakage (A), WST-1 test (B) and albumin production (C) in primary cultures of rat hepatocytes exposed to OA, PA and combinations of OA:PA $-3: 1 ; 2: 1$ and $1: 1$ at final concentrations of $0.125-2 \mathrm{mmol} / \mathrm{l}$ for $24 \mathrm{~h} ; \mathrm{n} \geq 12$ (Fig. $1 \mathrm{~A}$ and $1 \mathrm{~B}$ ) or $\mathrm{n} \geq 6$ (1C). Results are standardized to protein level and expressed as \% of control. Statistical significance is shown as $* * * \mathrm{p}<0.001$; $* \mathrm{p}<0.05$ vs. control; $+++\mathrm{p}<0.001 ;++\mathrm{p}<0.01 ;+\mathrm{p}<0.05$ vs. $\mathrm{PA}$ alone at the same final concentration and $0 \circ 0 \mathrm{p}<0.001$; $\circ \mathrm{p}<0.05$ vs. combination of OA:PA - 1:1 at the final concentration two times higher than $\mathrm{OA}$ alone or PA alone.
PA in the mixture at ratio $1: 1$ and final concentration of the mixture $0.5 \mathrm{mmol} / \mathrm{l}$ as well as $1 \mathrm{mmol} / \mathrm{l}$ induced significantly lower LDH leakage than separate PA at the same concentration that is in the mixture $(p<0.05$ for $0.25 \mathrm{mM}$ PA, $\mathrm{p}<0.001$ for $0.5 \mathrm{mM} \mathrm{PA}$; Fig. 1A). Similarly, equimolar mixture of $\mathrm{FA}$ at the final concentration of $0.5 \mathrm{mmol} / \mathrm{l}$ (i.e. $0.25 \mathrm{mM} \mathrm{OA}$ and $0.25 \mathrm{mM}$ PA) preserved the production of albumin nearly to the control level (Fig. 1C).

\section{Lipid accumulation}

Figure 2A documents steatosis and morphology of hepatocytes after the exposure to raising concentrations of OA or PA. Lipid accumulation was confirmed by oil red staining (not shown). TAG content was evaluated after exposure to fatty acids at the concentrations up to $1 \mathrm{mmol} / \mathrm{l}$ that were previously identified as cytotoxic for both OA and PA. Figure 2B indicates that TAG content in the hepatocytes raised dose-dependently, this increase was significant from $0.25 \mathrm{mM}$ PA $(\mathrm{p}<0.01)$ and $0.5 \mathrm{mM} \mathrm{OA}$ $(\mathrm{p}<0.001)$. At $0.5 \mathrm{mM}$ concentration, palmitic acid caused higher TAG accumulation in the liver cells than oleic acid $(p<0.05)$. On the contrary, oleic acid was more steatogenic than PA at 0.75 and $1 \mathrm{mM}$ concentrations $(\mathrm{p}<0.001)$. As various combinations of $\mathrm{OA}$ and $\mathrm{PA}$ were tested, TAG accumulation did not differ with decreasing proportion of OA. Combinations of OA and PA at ratios 1:1, 2:1 and 3:1 at the final concentration of $0.5 \mathrm{mmol} / \mathrm{l}$ exhibited similar TAG content as OA alone or PA alone at concentration of $0.5 \mathrm{mmol} / \mathrm{l}$. These combinations at final concentrations of 0.75 and $1 \mathrm{mmol} / 1$ induced TAG accumulation comparable only to separate OA while TAG formation after exposure to PA at appropriate concentrations was lower ( $\mathrm{p}<0.001$ for all comparisons). Increasing of the concentration of individual or combined fatty acids in the medium from 0.75 to $1 \mathrm{mmol} / \mathrm{l}$ did not significantly enhance the TAG content in the cells (Fig. 2B).

\section{Apoptosis and ROS production}

Apoptosis was evaluated by activity of caspase 3. Palmitic acid enhanced the activity of executive caspase 3 from the concentration of $0.5 \mathrm{mmo} / 1$ $(\mathrm{p}<0.001)$ while oleic acid had no effect (Fig. 3A). Similar results were obtained for the production of ROS: the exposure to $\mathrm{PA}$ in concentrations of $0.5 \mathrm{mmol} / 1$ and higher was accompanied by an increase in ROS production when compared to controls $(p<0.001)$ (Fig. 3B). As various combinations of fatty acids were tested, only palmitic acid alone caused an increase in the 
production of ROS and in the activity of caspase 3 $(p<0.001)$, whereas the combinations including oleic acid did not (Fig. 3A and 3B). Furthermore, mixture of fatty acids $1: 1$ at final concentration of $1 \mathrm{mmol} / 1$ (i.e. $0.5 \mathrm{mM}$
$\mathrm{OA}$ and $0.5 \mathrm{mM} \mathrm{PA}$ ) prevented the cells against formation of ROS and the activation of caspase 3 that we observed after exposure to only $0.5 \mathrm{mM}$ PA alone.

\section{A}

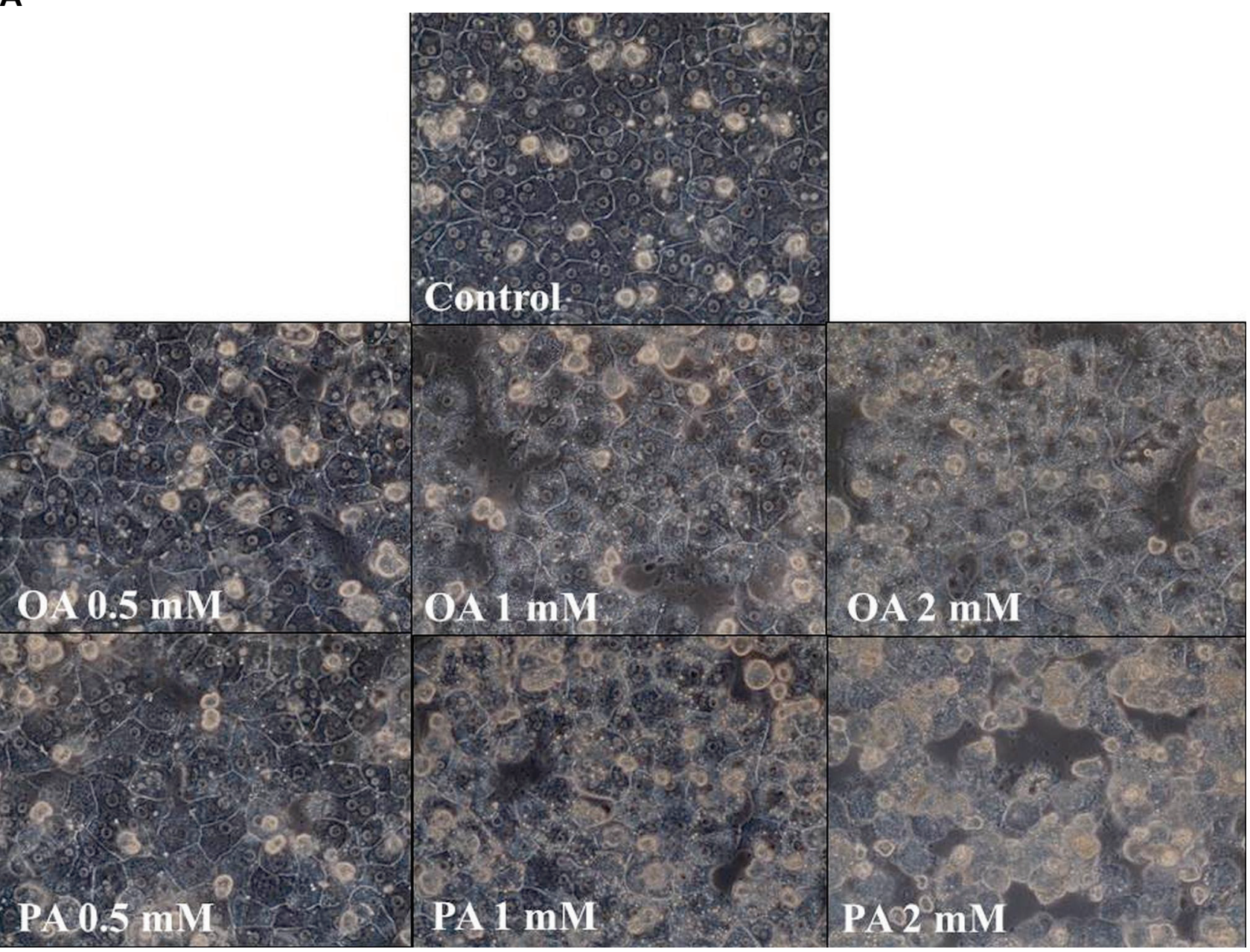

B

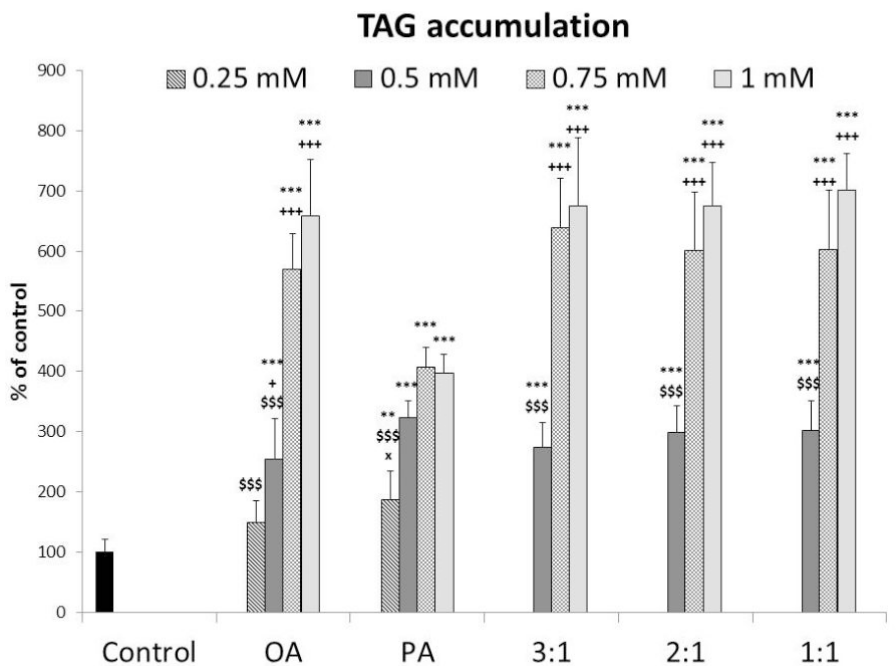

Fig. 2. Morphology of control hepatocytes and hepatocytes exposed to OA or PA at concentrations of $0.5,1$ and $2 \mathrm{mmol} / \mathrm{l}$ for $24 \mathrm{~h}$. Magnification is $400 \mathrm{x}$ (A). TAG accumulation (B) in primary rat hepatocytes exposed to $\mathrm{OA}, \mathrm{PA}$ and their combinations OA:PA - 3:1; $2: 1$ and $1: 1$ at total concentrations of $0.25-1 \mathrm{mmol} / \mathrm{l}$ for $24 \mathrm{~h}$. Results are standardized to protein levels and expressed as \% of control $(n \geq 6)$. Statistical significance is shown as $* * * \mathrm{p}<0.001 ; \quad * * \mathrm{p}<0.01$ vs. control; $+++\mathrm{p}<0.001$; $+p<0.05$ vs. PA alone at the same final concentration, $\$ \$ \$<0.001$ vs. same combination of OA:PA at the final concentration of 0.75 and $1 \mathrm{mmol} / \mathrm{l}$ and $x p<0.05$ vs. same combination of $\mathrm{OA}: \mathrm{PA}$ at the final concentration of $0.5 \mathrm{mmol} / \mathrm{l}$. 
A

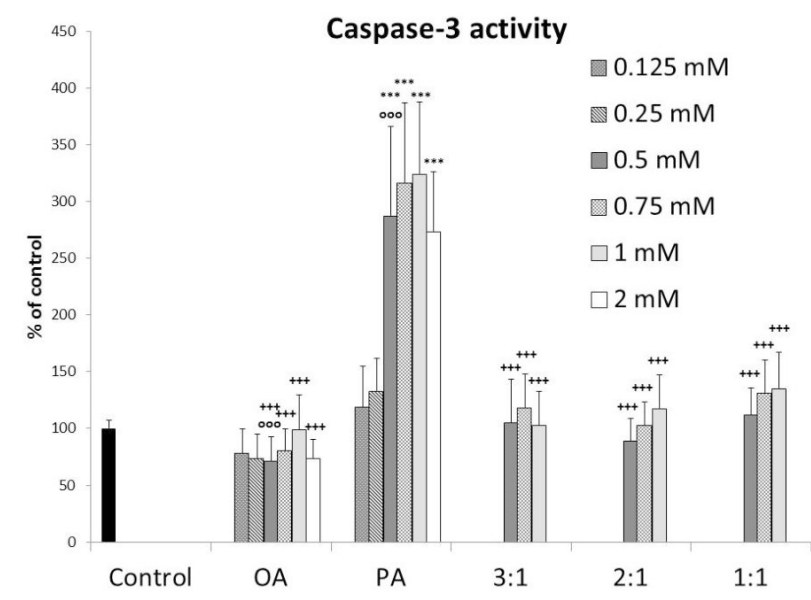

B

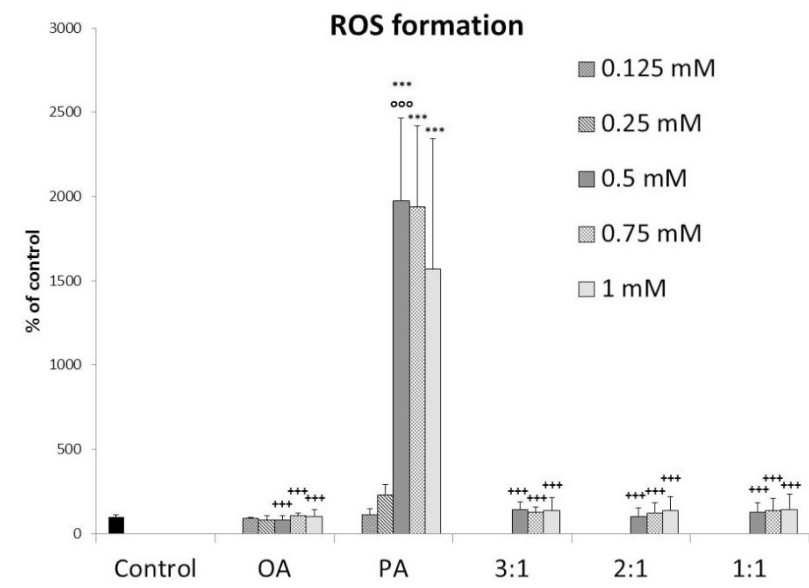

Fig. 3. Caspase 3 activity (A) and ROS production (B) in primary cultures of rat hepatocytes after treatment with OA, PA and combinations of OA:PA $-3: 1 ; 2: 1$ and $1: 1$ at final concentrations of $0.125-2 \mathrm{mmol} / \mathrm{l}$ for $24 \mathrm{~h}$. Results are standardized to protein level and expressed as \% of control $(n \geq 6)$. Statistical significance is shown as $* * * p<0.001$ vs. control; $+++p<0.001$ vs. PA alone at the same final concentration and $000 \mathrm{p}<0.001$ vs. combination $\mathrm{OA}: \mathrm{PA}-1: 1$ at the final concentration two times higher than OA alone or PA alone.

\section{Mitochondrial membrane potential}

We also evaluated the mitochondrial membrane potential using the fluorescent dye JC-1. Oleic acid did not change the mitochondrial membrane potential while the exposure of cells to palmitic acid in the concentration of $0.75 \mathrm{mmol} / \mathrm{l}$ and higher led to its significant decrease $(p<0.001)$. Again, any combination of fatty acids containing $\mathrm{OA}$ did not attenuate the mitochondrial membrane potential (Figs 4A and 4B).

\section{Discussion}

Non-alcoholic fatty liver disease (NAFLD) is characterized by the accumulation of triacylglycerols
(TAG) in the liver. In vitro models of steatosis are based on fat-overloading of cells. OA or PA can induce steatosis separately as well as in a mixture in hepatocyte primary cultures or in hepatoma cell lines (Joshi-Barve et al. 2007, Berthiaume et al. 2009, Gómez-Lechón et al. 2007, Mei et al. 2011, Ricchi et al. 2009). However, the effect of PA and OA on the development of steatosis, impact on functional capacity and cytotoxicity in rat hepatocytes in primary culture with regard to the dose of fatty acids was not described sufficiently.

In our study, the addition of $\mathrm{PA}$ or $\mathrm{OA}$ to primary culture of rat hepatocytes for $24 \mathrm{~h}$ led to a dosedependent increase in TAG content in hepatocytes. At low concentrations $(0.25$ and $0.5 \mathrm{mmol} / \mathrm{l}) \mathrm{PA}$ acts as a greater steatogenic agent than $\mathrm{OA}$ and at high concentrations $(0.75$ and $1 \mathrm{mmol} / \mathrm{l})$, the steatogenic effect is more pronounced in OA. This is in agreement with results of others documented on HepG2 and WRL-68 cells (Malhi et al. 2006, Ricchi et al. 2009). Rising concentrations of saturated PA can attenuate the synthesis of TAG in goose hepatocytes (Pan et al. 2011) by an effect on diglyceride acyltransferase from the group of enzymes involved in synthesis of TAG. The fact that PA is not able to induce TAG synthesis as effectively as OA was documented also in HepG2 cells (Ricchi et al. 2009) and in rat hepatoma cells H4IIEC3 (Leamy et al. 2014). The interruption of TAG synthesis has been also reported after the exposure to another saturated fatty acid, namely to stearic acid (Mantzaris et al. 2011). Accumulation of TAG induced by OA could be at least partly explained by the increase in sterol regulatory element-binding protein-1 and peroxisome proliferator-activated receptor gamma expression that act as lipogenic transcription factors (Ricchi et al. 2009). TAG content in hepatocytes exposed to the mixture of $\mathrm{OA}$ and PA depended on its final concentration in our study. It was comparable with values achieved after the incubation with OA alone. Moreover, increasing portion of OA did not affect the degree of steatosis.

Our results confirmed PA as a considerable cytotoxic agent in agreement with literature data on hepatoma cell lines and on human hepatocyte primary cultures (Mei et al. 2011, Malhi et al. 2006). PA decreased WST-1 in rat hepatocytes more rapidly than OA. LDH leakage rose after the exposure to PA at $0.25 \mathrm{mmol} / 1$ and higher dose-dependently. OA induced LDH leakage from a concentration of $1 \mathrm{mmol} / \mathrm{l}$. After the treatment with fatty acids (especially with PA) higher LDH leakage was accompanied by attenuated functional 
A

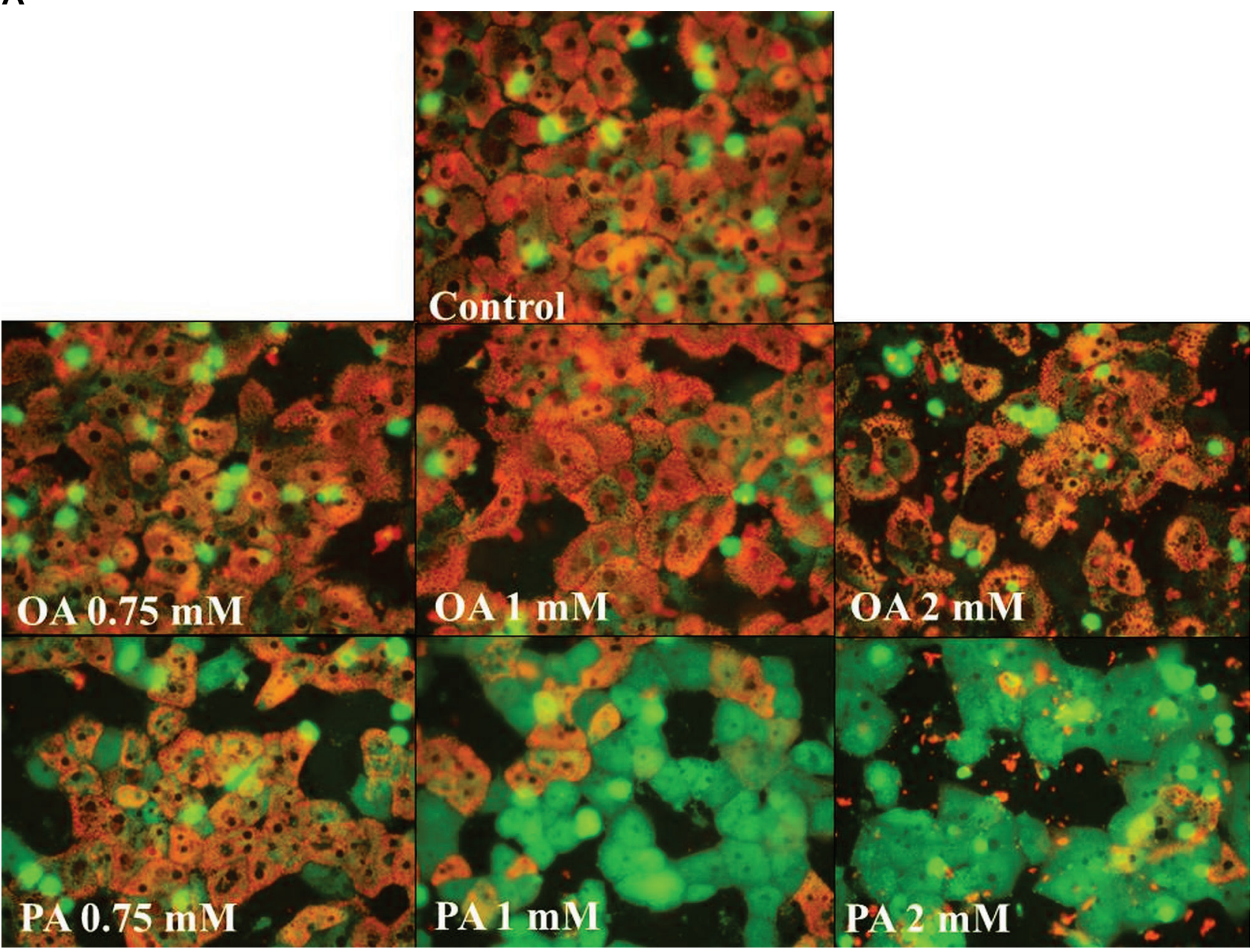

B

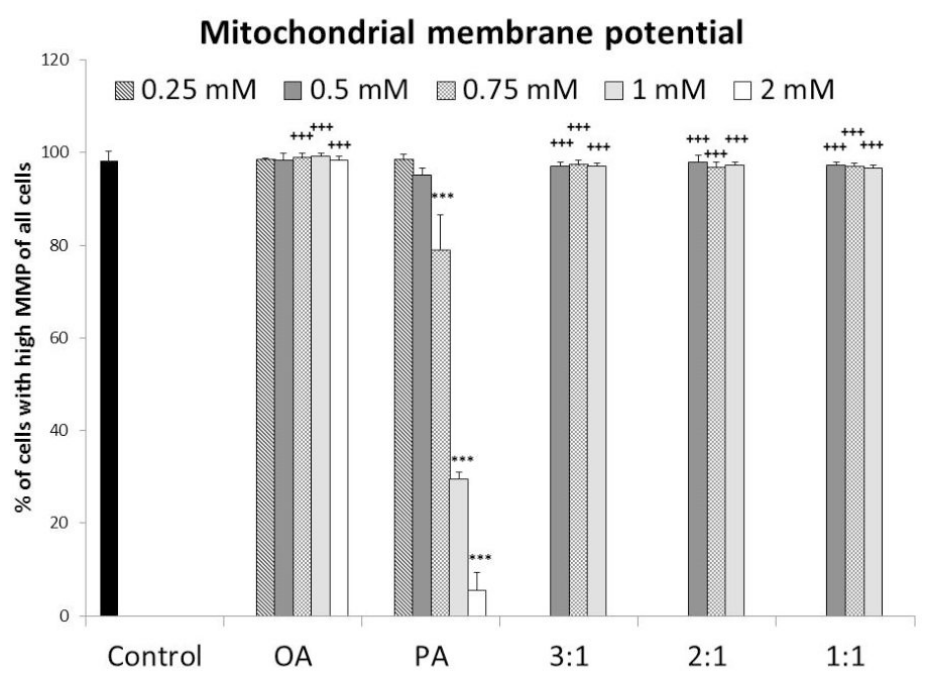

Fig. 4. Mitochondrial membrane potential was visualized by JC- 1 (magnification of photos is $400 \mathrm{x}$ ) (A) and $\%$ of cells with high membrane potential was counted $(n \geq 5)$ (B). Primary rat hepatocytes were treated with $O A, P A$ and their combinations in the ratio of OA:PA - 3:1; $2: 1$ and $1: 1$ at final concentrations of $0.25-2 \mathrm{mmol} / \mathrm{l}$ for $24 \mathrm{~h}$. Statistical significance is shown as $* * * p<0.001$; $* * p<0.01 ; \quad * p<0.05$ vs. control; $+++p<0.001$; Control

OA $+p<0.05$ vs. PA alone at the same final concentration.

capacity of rat hepatocytes when compared to controls. There is rising evidence that incorporation of fatty acids into TAG could act as a protective mechanism against free fatty acids-induced cytotoxicity (Trauner et al. 2010, Ricchi et al. 2009, Yamaguchi et al. 2007). In our study, hepatocytes exposed to PA at concentrations of 0.25 and
$0.5 \mathrm{mmol} / 1$ exhibited higher content of TAG together with more pronounced cytotoxicity than hepatocytes treated with $\mathrm{OA}$ at the same concentrations. Thus, the synthesis of TAG from free fatty acids does not necessarily guarantee protection of hepatocytes against free fatty acids-induced toxicity. 
$\mathrm{LDH}$ is released as a result of cytoplasmic membrane disruption and is a feature of necrosis (Gores et al. 1990). Moreover, cytotoxicity of saturated fatty acids is accompanied by apoptosis (Gómez-Lechón et al. 2007, Malhi et al. 2006, Ricchi et al. 2009). Our data confirmed a significant rise of executive caspase 3 activity after the exposure of rat hepatocytes to PA. On the contrary, OA did not induce caspase 3 activity. Other authors agreed that OA does not induce apoptosis or only at a low degree (Kong and Rabkin 2002, Ricchi et al. 2009, Sparagna et al. 2001). The mechanisms of the proapoptotic action of PA are not completely understood but mitochondria play an important role. Saturated fatty acids are potent inducers of endoplasmic reticulum stress in hepatic cells leading to an efflux of calcium (Zhang et al. 2012, Leamy et al. 2014). It was documented that PA in a complex with calcium induces opening of permeability transition pore that lead to a fall in mitochondrial membrane potential and a release of cytochrome $\mathrm{c}$ from the mitochondria (Belosludtsev et al. 2006, 2014). Our results showed a dose-dependent decrease in the mitochondrial membrane potential after exposure of rat hepatocytes to PA. We noted a nearly complete loss of this potential from $1 \mathrm{mM} P A$. In the case of OA, the mitochondrial membrane potential was preserved.

Oxidative stress seems to be a powerful stimulus able to trigger the apoptotic cascade in cells. The exposure to PA led to ROS formation (Listenberger et al. 2001). We document here that PA-induced production of ROS corresponds with the increased caspase 3 activity. On the contrary, the incubation of rat hepatocytes with $\mathrm{OA}$ in concentrations from 0.125 to $1 \mathrm{mmol} / 1 \mathrm{did}$ not either induce the ROS production or caspase 3 activity.

In our study, the mixture of $\mathrm{OA}$ and $\mathrm{PA}$ at the final concentrations of $0.5,0.75$ and $1 \mathrm{mmol} / 1$ exhibited lower cytotoxicity than is induced by $\mathrm{PA}$ alone in equal concentrations. Interestingly, even if OA was in the mixture with PA at equimolar ratio, the cytotoxicity was significantly lower than after PA alone, even though the total fatty acid concentration was twice as high; this suggests a protective effect of OA in these conditions. The mixture of OA and PA actually prevented the cells from ROS production and caspase 3 activation. The attenuation of cytotoxicity was accompanied by a preservation of albumin production in rat hepatocytes. PA-induced decline in mitochondrial membrane potential, apoptotic caspase activation and cell death are closely associated with the changes of cellular phospholipid composition (Leamy et al. 2014). The addition of OA to PA in the study of Leamy et al. (2014) resulted in a reduction in $\mathrm{PA}$ incorporation into cellular phospholipids and in an increase in TAG esterification. Thus the prevention of PA-induced incorporation of saturated phospholipids into the cellular membranes by OA could play a role in the attenuation of ROS production and of the caspase activity. Moreover, prevention of the palmitate-induced mitochondrial dysfunction and preservation of ATP production were described in mouse neuroblastoma cells preconditioned with OA (Kwon et al. 2014). As it was mentioned, relatively higher TAG content induced by $\mathrm{OA}$ can also play a role.

Based on our study the exposure of rat hepatocytes to oleic and/or palmitic acid induces the development of steatosis in primary culture dosedependently. Palmitic acid exhibits a dose-dependent cytotoxic effect associated with ROS production, present markers of both apoptosis and necrosis together with a decreased albumin production. OA and PA in the mixture allow to develop steatosis associated with lower toxicity and better preserved functional capacity of hepatocytes. Therefore, simple steatosis can be induced by $\mathrm{OA}$ or $\mathrm{OA}$ in combination with $\mathrm{PA}$. This in vitro model could allow studying to what extent and by which mechanisms even simple steatosis predisposes hepatocytes to higher susceptibility to toxic damage. Such knowledge is a prerequisite for better preservation of steatotic hepatocytes.

\section{Conflict of Interest}

There is no conflict of interest.

\section{Acknowledgements}

PRVOUK P37/02

\section{References}

ARAYA J, RODRIGO R, VIDELA LA, THIELEMANN L, ORELLANA M, PETTINELLI P, PONIACHIK J: Increase in long-chain polyunsaturated fatty acid $n-6 / n-3$ ratio in relation to hepatic steatosis in patients with non-alcoholic fatty liver disease. Clin Sci (Lond) 106: 635-643, 2004. 
BELOSLUDTSEV K, SARIS NE, ANDERSSON LC, BELOSLUDTSEVA N, AGAFONOV A, SHARMA A, MOSHKOV DA, MIRONOVA GD: On the mechanism of palmitic acid-induced apoptosis: the role of a pore induced by palmitic acid and $\mathrm{Ca}^{2+}$ in mitochondria. J Bioenerg Biomembr 38: 113-120, 2006.

BELOSLUDTSEV KN, BELOSLUDTSEVA NV, AGAFONOV AV, ASTASHEV ME, KAZAKOV AS, SARIS NE, MIRONOVA GD: $\mathrm{Ca}(2+)$-dependent permeabilization of mitochondria and liposomes by palmitic and oleic acids: a comparative study. Biochim Biophys Acta 1838: 2600-2606, 2014.

BERRY MN, EDWARDS AM, BARRITT GJ: High-yield preparation of isolated hepatocytes from rat liver. In: Isolated Hepatocytes: Preparation, Properties and Applications. BURDON RH, VAN KNIPPENBERG PH (eds), Elsevier, New York, 1991, pp 15-58.

BERTHIAUME F, BARBE L, MOKUNO Y, MACDONALD AD, JINDAL R, YARMUSH ML: Steatosis reversibly increases hepatocyte sensitivity to hypoxia-reoxygenation injury. J Surg Res 152: 54-60, 2009.

BRADFORD MM: A rapid and sensitive method for the quantitation of microgram quantities of protein utilizing the principle of protein-dye binding. Anal Biochem 72: 248-254, 1976.

BRAUNERSREUTHER V, VIVIANI GL, MACH F, MONTECUCCO F: Role of cytokines and chemokines in nonalcoholic fatty liver disease. World J Gastroenterol 18: 727-735, 2012.

GAMBINO R, MUSSO G, CASSADER M: Redox balance in the pathogenesis of nonalcoholic fatty liver disease: mechanisms and therapeutic opportunities. Antioxid Redox Signal 15: 1325-1365, 2011.

GARNOL T, ENDLICHER R, KUČERA O, DRAHOTA Z, ČERVINKOVÁ Z: Impairment of mitochondrial function of rat hepatocytes by high fat diet and oxidative stress. Physiol Res 63: 271-274, 2014.

GÓMEZ-LECHÓN MJ, DONATO MT, MARTINEZ-ROMERO A, JIMÉNEZ N, CASTELL JV, O'CONNOR JE: A human hepatocellular in vitro model to investigate steatosis. Chem Biol Interact 165: 106-116, 2007.

GORES GJ, HERMAN B, LEMASTERS JJ: Plasma membrane bleb formation and rupture: a common feature of hepatocellular injury. Hepatology 11: 690-698, 1990.

JOSHI-BARVE S, BARVE SS, AMANCHERLA K, GOBEJISHVILI L, HILL D, CAVE M, HOTE P, MCCLAIN CJ: Palmitic acid induces production of proinflammatory cytokine interleukin-8 from hepatocytes. Hepatology $\mathbf{4 6}$ : 823-830, 2007.

KAISEROVÁ H, DEN HARTOG GJ, ŠIMUNEK T, SCHROTEROVÁ L, KVASNIČKOVÁ E, BAST A: Iron is not involved in oxidative stress-mediated cytotoxicity of doxorubicin and bleomycin. Br J Pharmacol 149: 920930, 2006.

KON K, IKEJIMA K, OKUMURA K, ARAI K, AOYAMA T, WATANABE S: Diabetic KK-A(y) mice are highly susceptible to oxidative hepatocellular damage induced by acetaminophen. Am J Physiol Gastrointest Liver Physiol 299: G329-G337, 2010.

KONG JY, RABKIN SW: Lovastatin does not accentuate but is rather additive to palmitate-induced apoptosis in cardiomyocytes. Prostaglandins Leukot Essent Fatty Acids 67: 293-302, 2002.

KUČERA O, LOTKOVÁ H, STAŇKOVÁ P, PODHOLA M, ROUŠAR T, MEZERA V, ČERVINKOVÁ Z: Is rat liver affected by non-alcoholic steatosis more susceptible to the acute toxic effect of thioacetamide? Int $J$ Exp Pathol 92: 281-289, 2011.

KUČERA O, AL-DURY S, LOTKOVÁ H, ROUŠAR T, RYCHTRMOC D, ČERVINKOVÁ Z: Steatotic rat hepatocytes in primary culture are more susceptible to the acute toxic effect of acetaminophen. Physiol Res $\mathbf{6 1}$ (Suppl 2): S93-S101, 2012.

KUČERA O, ENDLICHER R, ROUŠAR T, LOTKOVÁ H, GARNOL T, DRAHOTA Z, ČERVINKOVÁ Z: The effect of tert-butyl hydroperoxide-induced oxidative stress on lean and steatotic rat hepatocytes in vitro. Oxid Med Cell Longev 2014: Article ID 752506, 2014.

KWON B, LEE HK, QUERFURTH HW: Oleate prevents palmitate-induced mitochondrial dysfunction, insulin resistance and inflammatory signaling in neuronal cells. Biochim Biophys Acta 1843: 1402-1413, 2014.

LEAMY AK, EGNATCHIK RA, SHIOTA M, IVANOVA PT, MYERS DS, BROWN HA, YOUNG JD: Enhanced synthesis of saturated phospholipids is associated with ER stress and lipotoxicity in palmitate treated hepatic cells. J Lipid Res 55: 1478-1488, 2014.

LISTENBERGER LL, ORY DS, SCHAFFER JE: Palmitate-induced apoptosis can occur through a ceramideindependent pathway. $J$ Biol Chem 276: 14890-14895, 2001. 
LOTKOVÁ H, KUČERA O, ROUŠAR T, ENDLICHER R, KŘIVÁKOVÁ P, GARNOL T, ČERVINKOVÁ Z: Effect of S-adenosylmethionine on acetaminophen-induced toxic injury of rat hepatocytes in vitro. Acta Vet Brno 78: 603-613, 2009.

MALHI H, BRONK SF, WERNEBURG NW, GORES GJ: Free fatty acids induce JNK-dependent hepatocyte lipoapoptosis. J Biol Chem 281: 12093-12101, 2006.

MANTZARIS MD, TSIANOS EV, GALARIS D: Interruption of triacylglycerol synthesis in the endoplasmic reticulum is the initiating event for saturated fatty acid-induced lipotoxicity in liver cells. FEBS J 278: 519-530, 2011.

MEI S, NI HM, MANLEY S, BOCKUS A, KASSEL KM, LUYENDYK JP, COPPLE BL, DING WX: Differential roles of unsaturated and saturated fatty acids on autophagy and apoptosis in hepatocytes. $J$ Pharmacol Exp Ther 339: 487-498, 2011.

NIKLAS J, BONIN A, MANGIN S, BUCHER J, KOPACZ S, MATZ-SOJA M, THIEL C, GEBHARDT R, HOFMANN U, MAUCH K: Central energy metabolism remains robust in acute steatotic hepatocytes challenged by a high free fatty acid load. BMB Rep 45: 396-401, 2012.

PAN Z, WANG J, TANG H, LI L, LV J, XIA L, HAN C, XU F, HE H, XU H, KANG B: Effects of palmitic acid on lipid metabolism homeostasis and apoptosis in goose primary hepatocytes. Mol Cell Biochem 350: 39-46, 2011.

RICCHI M, ODOARDI MR, CARULLI L, ANZIVINO C, BALLESTRI S, PINETTI A, FANTONI LI, MARRA F, BERTOLOTTI M, BANNI S, LONARDO A, CARULLI N, LORIA P: Differential effect of oleic and palmitic acid on lipid accumulation and apoptosis in cultured hepatocytes. J Gastroenterol Hepatol 24: 830-840, 2009.

ROGUE A, ANTHERIEU S, VLUGGENS A, UMBDENSTOCK T, CLAUDE N, DE LA MOUREYRE-SPIRE C, WEAVER RJ, GUILLOUZO A: PPAR agonists reduce steatosis in oleic acid-overloaded HepaRG cells. Toxicol Appl Pharmacol 276: 73-81, 2014.

SPARAGNA GC, HICKSON-BICK DL, BUJA LM, MCMILLIN JB: Fatty acid-induced apoptosis in neonatal cardiomyocytes: redox signaling. Antioxid Redox Signal 3: 71-79, 2001.

SWAGELL CD, HENLY DC, MORRIS CP: Expression analysis of a human hepatic cell line in response to palmitate. Biochem Biophys Res Commun 328: 432-441, 2005.

TANG Y, BIAN Z, ZHAO L, LIU Y, LIANG S, WANG Q, HAN X, PENG Y, CHEN X, SHEN L, QIU D, LI Z, MA X: Interleukin-17 exacerbates hepatic steatosis and inflammation in non-alcoholic fatty liver disease. Clin Exp Immunol 166: 281-290, 2011.

TOLMAN KG, DALPIAZ AS: Treatment of non-alcoholic fatty liver disease. Ther Clin Risk Manag 3: 1153-1163, 2007.

TRAUNER M, ARRESE M, WAGNER M: Fatty liver and lipotoxicity. Biochim Biophys Acta 1801: 299-310, 2010.

VENDEMIALE G, GRATTAGLIANO I, CARACENI P, CARACCIO G, DOMENICALI M, DALL'AGATA M, TREVISANI F, GUERRIERI F, BERNARDI M, ALTOMARE E: Mitochondrial oxidative injury and energy metabolism alteration in rat fatty liver: effect of the nutritional status. Hepatology 33: 808-815, 2001.

VIDELA LA, RODRIGO R, ARAYA J, PONIACHIK J: Oxidative stress and depletion of hepatic long-chain polyunsaturated fatty acids may contribute to nonalcoholic fatty liver disease. Free Radic Biol Med 37: 14991507, 2004.

YAMAGUCHI K, YANG L, MCCALL S, HUANG J, YU XX, PANDEY SK, BHANOT S, MONIA BP, LI YX, DIEHL AM: Inhibiting triglyceride synthesis improves hepatic steatosis but exacerbates liver damage and fibrosis in obese mice with nonalcoholic steatohepatitis. Hepatology 45: 1366-1374, 2007.

ZHANG Y, XUE R, ZHANG Z, YANG X, SHI H: Palmitic and linoleic acids induce ER stress and apoptosis in hepatoma cells. Lipids Health Dis 11: 1, 2012. 